\title{
NILAI-NILAI KARAKTER YANG TERKANDUNG DALAM DOLANAN ANAK PADA FESTIVAL DOLANAN ANAK SE-DIY 2013
}

\author{
Enis Niken Herawati \\ FBS Universitas Negeri Yogyakarta \\ email : enisniken@yahoo.com
}

\begin{abstract}
ABSTRAK
Tujuan jangka panjang diadakannya Festifal Dolanan Anak adalah pengenalan dan pelestarian dolanan anak agar tetap berkembang di masyarakat, setidaknya dikenal dengan baik oleh generasi muda. Penelitian ini memiliki dua tujuan yakni 1) menjelaskan bentuk penyajian dolanan anak pada festifal dolanan anak DIY tahun 2013. Hasil yang diperoleh berupa bentuk atau wujud dolanan dan aturan mainnya, 2) menjelaskan nilai karakter yang terkandung di dalam dolanan anak pada festifal dolanan anak yang terinci dalam nilai afektif, kognitif, dan psikomotorik. Sesungguhnya nilai yang terdapat dalam dolanan anak sangat beragam. Kaitannya dengan seni pertunjukkan yang mengedepankan wiraga, wirasa, dan wirama maka nilai dalam dolanan diarahkan dalam bentuk afektif, kognitif, dan psikomotorik.

Data penelitian ini berupa deskriptif kualitatif yaitu menjelaskan data temuan melalui kata-kata bukan angka. PEngumpulan data dilakukan dengan cara observasi, wawancara, studi pustaka. Nilai karakter dapat digali dengan cara pemaknaan secara induksi, emnggunakan kamus untuk mengartikan kata-kata yang terdapat dalam lirik lagu. Sementara untuk gerakan dolanan anak digunakan teori semiotic (non verbal) dalam pemaknaannya. Tiap gerakan dari dolanan anak adalah interpretasi dari bentuk dolanan itu sendiri

Hasil dari penelitian yaitu temuan nilai karakter dari tiap-tiap dolanan anak. Dolanan anak Cublak-cublk uwung memiliki nilai karakter setidaknya ada nilai kerjasama, keproaktifam, nilai keresponsifan, nilai kreatif dan nilai kecermatan. Jamuran memiliki sekurang-kurangnya nilai kerjasama, nilai kreatifitas, dan nilai tanggung jawab. Sementara untuk dolanan Ancak-ancak Alis memiliki nilai karakter seperti nilai kerjasama, nilai kecermatan dan nilai ketekunan.
\end{abstract}

Kata kunci: nilai atau karakter, dolanan anak, festival (seni pertunjukan)

The Character Values Found in Dolanan Anak

in Yogyakarta Dolanan Anak Festival in 2013

\section{ABSTRACT}

This main purpose of the research is to describe about Dolanan Anak character values. Dolanan Anak festival was a series of activities carried out in the collaboration between the Department of Tourism and Taman Budaya Yogyakarta dealing with the activation of Taman Budaya Yogyakarta. The number of visitors and participants of the Dolanan Anak Festival made the event so highly waited by several art groups, observers, and public in general. Many people are concerned with the importance of dolanan anak because the values containing in it are still relevant to contemporary life. 
This research was conducted to clarify how in the previous era dolanan anak was used as the medium for kids to gather and have fun. The sense of satisfaction after playing with friends gives "addicted" effect and the dolanan is played repeatedly, which is largely not being realized directly by the children. The initial explanation about Jamuran, CublakCublak Suweng and Ancak-Ancak Alis kid's game is in the form of the presentation in the Dolanan Anak Festival and the game rules. The next explanation is related to the character values in dolanan anak (Java). The researcher delivers thanks for all who have helped so that this research could be conducted well. The researcher realizes that there are many inadequacies in reporting the result of this study. Thus, the researcher kindly needs criticism and constructive suggestions for the next improvement.

Key Words : Character value, Dolanan Anak, Festival

\section{A. PENDAHULUAN}

Secara sederhana dolanan anak memiliki fungsi, baik fungsi umum (rekreasi) maupun fungsi khusus (edukasi). Beberapa ahli mengemukakan pendapatnya bahwa dolanan mampu mengembangkan pikiran dan kreatifitas serta mengajarkan nilai moral ke anak-anak. Banyaknya fungsi di dalam dolanan anak menjadi ketertarikan peneliti untuk dijadikan latar belakang dalam kajian ini. Fungsi utama dolanan anak adalah untuk rekreasi atau menyenangkan hati. Dalam hal ini menjelaskan bahwa bermain menyebabkan hati riang dan keinginan untuk terus melakukannya. Fungsi dolanan anak yang lain, antara lain edukasi, sosial, folkor, dan psikologi. Fungsi edukasi dari dolanan anak berhubungan dengan mempelajari hal-hal baru berkaitan dengan bentuk, warna, ukuran, dan tekstur suatu benda. Semakin besar anak mengembangkan berbagai keterampilan baru dalam permainan maka kesempatan tersebut banyak membantu pengembangan diri anak yang tidak bisa mereka peroleh melalui pembelajaran di sekolah atau dipelajari lewat buku.

Bermain dengan teman sebaya membuat anak belajar bagaimana membangun suatu hubungan sosial dengan anak-anak lain yang belum dikenalnya dan bagaimana mengatasi berbagai persoalan yang ditimbulkan oleh hubungan tersebut. Melalui permainan kooperatif, misalnya anak belajar memberi dan menerima. Fungsi permainan dipandang dari segi psikologi yaitu untuk menumbuhkan perkembangan jiwa dan nalar anak-anak. Fungsi folkor dari dolanan anak, khususnya di Jawa merupakan pelestarian unsur budaya yang dikenal dengan akrab dipandang sebagai hal yang sangat penting. Permainan tradisional tampaknya merupakan salah satu budaya yang masih dilestarikan dengan berbagai macam simbol yang 
mampu menampilkan identitas. Buktinya, dolanan anak tradisional umumnya menggunakan bahasa daerah, sehingga ciri budaya lokalnya menjadi tampak jelas

Sejak tahun 2010, Daerah Istimewa Yogyakarta mengadakan pagelaran atau pertunjukan yang mengangkat tema seni dan tradisi. Acara ini merupakan acara rutin yang bekerja sama dengan berbagai pihak baik swasta maupun pemerintah. Taman Budaya Yogyakarta yang bekerja sama dengan Dinas Pariwasata DIY menggelar acara Festival Dolanan Anak pada tahun 2013. Acara ini berlangsung selama tiga hari dengan peserta puluhan grup atau kelompok seni dari lima kabupaten di Yogyakarta. Hal tersebut mengindikasikan secara positif bahwa keberadaan dolanan anak-anak perlu dipedulikan supaya tidak punah. Studi ini akan lebih diarahkan pada upaya menggali nilai-nilai karakter yang terkandung dalam gerak tari pada dolanan anak yang dikemas dalam Festival Dolanan Anak yang berlangsung di Taman Budaya Yogyakarta pada tahun 2013.

\section{B. METODE PENELITIAN}

Berdasarkan latar belakang masalah di atas, peneliti memfokuskan pada penelitian deskriptif kualitatif yang bertujuan untuk mengungkapkan nilai-nilai karakter yang terkandung dalam Dolanan Anak pada Festival Dolanan Anak se-DIY 2013. Penelitian ini sengaja membatasi objek kajiannya pada bentuk penyajian dolanan anak yang berhasil dinyatakan menjadi juara 1 atau penampil terbaik di Festival Dolanan Anak tahun 2013.

Penelitian ini diharapkan bermanfaat secara teoretis maupun praktis. Manfaat secara teoretis agar penelitian ini diharapkan dapat menambah khasanah pengetahuan tentang dunia anak-anak pada umumnya dan dolanan anak-anak pada khususnya. Manfaat secara praktis agar hasil penelitian ini diharapkan dapat bermanfaat bagi para pemangku kepentingan (stakeholders) sebagai bentuk penyadaran dan pencerahan bahwa di dalam dolanan anakanak terkandung nilai-nilai karakter yang teramat strategis bagi penanaman, pembentukan, atau penguatan jatidiri. Sehingga, tidak ada alasan lain kecuali menaruh perhatian dan kepedulian mereka untuk secara sungguh-sungguh dan konsisten melestarikan dan mengembangkan dolanan anak.

\section{LANDASAN TEORI}

\section{Dolanan Anak}

Kajian permainan anak telah banyak dilakukan oleh beberapa ahli baik di bidang seni dan budaya ataupun psikologi. Hal ini berarti permainan anak dapat dilihat dari beberapa 
aspek atau paradigma. Kajian permainan anak menurut Ahimsha (1999: 15) dapat dilihat dari berbagai perspektif sebagai berikut.
a. Perspektif Fungsional : persiapan menjadi dewasa
b. Perspektif bermain : permainan 'game'
c. Persepektif Psikologis : wujud kecemasan dan kemarahan
d. Persepektif Adaptasi : peningkatan kemampuan adaptasi

Hampir seluruh permainan anak yang ada di DIY memiliki unsur-unsur di atas. Bahkan ada beberapa permainan yang memiliki 2-3 unsur di dalamnya. Tentunya semakin banyak unsur positif yang terkandung di dalam permainan anak, akan semakin baik untuk dikembangkan. Tidak hanya permainan anak yang dilestarikan, juga menyiapkan anak-anak generasi penerus bangsa yang siap menghadapi perubahan jaman.

Dari berbagai referensi dan acauan dari tokoh, budayawan dan peneliti tentang dolanan anak dapat disimpulkan bahwa dolanan anak (permainan) dapat menumbuhkan 3 aspek diri, yaitu afektif; kognitif; dan psikomotorik. Semua dolanan anak paling tidak memiliki satu aspek, namun telah disinggung di awal semakin banyak aspek yang dapat ditumbuhkan dalam diri anak, semakin besar nilai yang terkandung di dalamnya.

\section{Gerak Tari}

Gerak merupakan unsur utama dari tari. Gerak di dalam tari bukanlah gerak yang realistis, melainkan gerak yang telah diberi bentuk ekspresif dan estetis (Murgiyanto, 1994: 19). Gerak tari selalu melibatkan unsur anggota badan manusia. Gerak dalam tari berfungsi sebagai media untuk mengomunikasikan maksud-maksud tertentu dari koreografernya. Gerak di dalam tari ialah gerak yang indah; gerak yang telah diberi sentuhan seni. Gerak-gerak keseharian yang telah diberi sentuhan seni akan menghasilkan gerak yang indah bila dipandang. Misalnya, gerak berjalan, lari, mencangkul, menimba air di sumur, memotong kayu, jika diberi sentuhan emosional yang mengandung nilai seni maka gerak-gerak keseharian tersebut akan tampak lain.

Gerakan badan yang ada ditampilkan dengan memperhatikan aspek seni tari wiraga, wirasa, dan wirama akan menjadi suatu gerakan yang baik. Gerakan badan dolanan anak akan nampak indah apabila dimainkan dengan segenap rasa, dengan nyanyian yang seirama dan bersama-sama. Hampir sebagian besar dolanan anak yang memerlukan nyanyian dalam aturan permainannya akan menggunakan gerakan yang indah dengan menyesuaikan liriknya. 


\section{Nilai Karakter}

Karakter merupakan sifat yang tampak dari seseorang saat berbicara atau bertingkah laku dalam kehidupan sehari-hari. Karakter dapat dibangun melalui penanaman baik langsung maupun tidak langsung. Melalui dolanan anak, nilai karakter dapat diberikan kepada anak, misalnya nilai sportivitas, nilai pendidikan, nilai gotong royong, nilai moral, dan nilai keberanian (Sujarno, dkk, 2011: 119).

Masing-masing dolanan anak memiliki aturan main yang berbeda, namun ada kesamaan dari beberapa nilai yang terkandung di dalamnya. Misalnya pada dolanan jamuran dan cublak-cublak suweng memiliki kesamaan nilai kerjasama, nilai kerukunan, nilai kreatifitas, dan sebagainya. Nilai-nilai tersebut dapat dimasukkan dalam tiga kategori: nilai afektif, nilai nilai kognitif dan nilai psikomotorik.

\section{Semiotik}

Kajian semiotik digunakan untuk menjelaskan nilai karakter yang terkandung di dalam dolanan anak. Semiotik merupakan bagian keilmuan yang dicetuskan oleh Ferdinand de Saussure (linguist) serta Roland Barthes (sastrawan). Ilmu penanda dan petanda yang dikenal sebagai semiotik digunakan untuk menjelaskan makna yang selain kata, misalnya benda, gerakan, atau simbol. Pada kajian ini akan mengggunakan pendapat Barthes (1970: 19-20), yang membagi kode menjadi lima, yakni a) Kode hermeneutik, b) Kode semik, c) Kode simbolis, d) kode aksi, dan e) Kode kultural. Adapun kajian yang akan diangkat berupa nilai karakter di dalam dolanan anak maka akan lebih relevan apabila menggunakan kode simbolis dan kode kultural.

Sebagian besar dolanan anak di dalam Festival Dolanan Anak berupa gerakan yang disertai nyanyian. Keduanya dilakukan bersama-sama dalam menjalankan dolanan anak. Untuk analisis semiotik dari dolanan anak diperoleh melalui menghimpun data yang berupa lirik dan gerakan kemudian menganalisis melalui kode simbolik ataupun kode kultural.

Sebagai contoh dalam dolanan Cublak-cublak Suweng, gerakan tangan seperti memutar batu ke telapak pemain selalu diawali dengan lirik “cublak cublak suweng, suwenge ting geleter.....”. Arti dari kalimat Cublak-cublak Suweng adalah ketuk, keruk. Gerakan memutar sambil menelungkupkan jari ialah gerakan yang sama dengan mengeruk aatau mengetuk sesuatu benda. Aturan permainan Cublak-cublak Suweng sesungguhnya telah jelas ditampilkan melalui lirik lagunya. Gerakan yang dipilih untuk menyeleraskan lirik adalah 
gerakan tangan layaknya orang mengeruk atau mengetuk sesuatu. Konsep atau petanda (signifie) dari permainan ini adalah mengeruk atau mengetuk benda, sedangkan penandanya (signifiant) berupa gerakan tangan dalam permainan Cublak-Cublak Suweng. Gerakan orang mengetuk atau mengeruk dalam permainan tersebut merupakan simbol dari lirik yang dinyanyikan.

Dalam analisis data dolanan anak nantinya memerlukan analisis kode simbolik atau kode kultural seperti teori Semiotik- Barthes. Dolanan anak bagian dari budaya, maka konsep kultural biasanya tampak di dalam unsur permainan anak. Sementara untuk lirik lagu atau nyanyian dalam dolanan anak lebih ke arah semantik sehingga pengecekan dan analisis makna seperti di dalam kamus. Adapun analisis yang mendalam dari lirik lagu dengan pertimbangan kognitif serta kode kultural untuk menguatkan hasil pemaknaan.

\section{PEMBAHASAN}

\section{Cublak-cublak Suweng}

Dolanan Cublak-cublak Suweng berasal dari Jawa. Cublak-cublak Suweng berasal dari kata cublak-cublak yang berarti tempat minyak wangi; dicublak artinya diketuk atau dikeruk. Suweng artinya perhiasan telinga. Cublak-cublak Suweng merupakan permainan yang pelaksanaannya dengan mengetuk-ngetuk dengan perlahan alat permainannya yang berupa subang atau uwer ke telapak tangan para pemain. Subang atau uwer saat ini sulit ditemukan, maka sebagai alat untuk bermain dapat pula diganti dengan kerikil atau biji-bijian. Selain perlengkapan tersebut, permainan ini juga menggunakan tembang dalam pelaksanaannya. Tempat pelaksanaannya bisa dimana saja, dan dapat dimainkan minimal tiga orang.

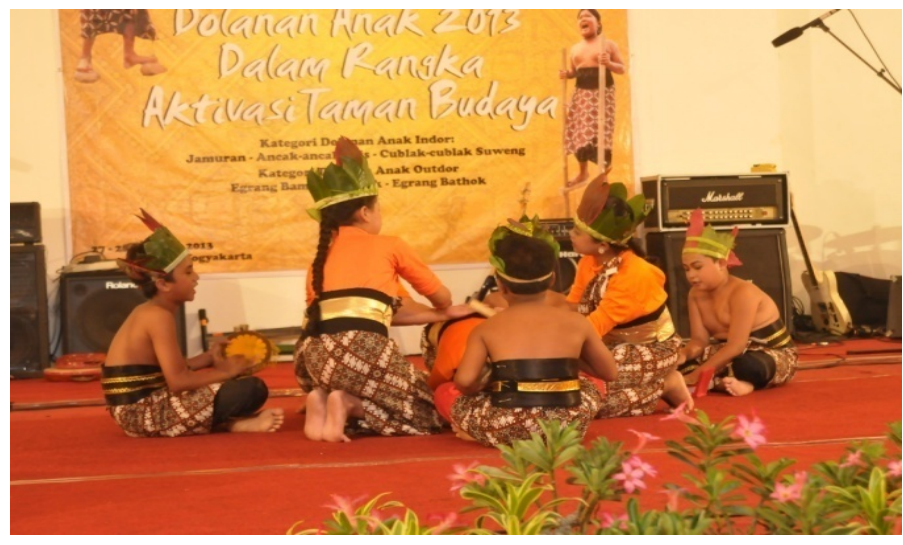

Gambar 1. Cublak-cublek Suweng (dok: disparDIY) 


\section{a. Bentuk Permainan}

Bentuk permainan dalam dolanan Cublak-cublak Suweng berupa lagu dan gerak tari. Lagu dolanan Cublak-cublak Suweng adalah sebagai berikut:

Cublak-cublaksuweng 'mengetuk-ngetukan subang'

Suwenge ting gelenter 'subangnya berserakan'

Mambu ketundhung gudel 'berbau anak kerbau yang terlepas'

Pak empong lera lere 'kempong bergerak ke sana ke mari'

Sapa ngguyu ndhelikkake 'siapa yang tertawa dia yang menyembunyikan'

Sir sir pong dhele kopong 'sir, sir pong kedelai kopong'

Sir sir pong dhele gosong 'sir, sir pong kedelai kopong'

Cara memainkan gerak pada dolanan Cublak-cublak Suweng, yaitu yang di tengah satu anak meringkuk (ndhekem), sedangkan pemain yang lain duduk mengelilingi. Salah satu pemain selama lagunya dinyanyikan memegang batu dan mengetukkan-ngetukkan perlahan batu tersebut ke telapak tangan pemain lainnya, termasuk salah satu telapak tanggannya sendiri. Setelah lagu yang dinyanyikan sampai pada kata pak empong lera lere, maka semua telapak tangan diangkat dari punggung yang di tengah dengan posisi tangan menggenggam. Gerak dan lagunya juga diiringi dengan alat musik, seperti kenthongan, terbang, dan saron kecil supaya suasana lebih hidup.

Lirik lagu Cublak-cublak Suweng yang cukup dikenal di masyarakat Jawa, secara keseluruhan menggunakan bahasa Jawa. Pada lirik pemaknaannya tidak dapat begitu saja diartikan, terkadang keterkaitan baris yang satu dengan yang lain tidak ditemukan dan sengaja memuncukan keindahan dengan rima. Permainan Cublak-cublak Suweng yang telah dijelaskan di awal, memutar batu (suweng) ke tangan pemain hingga nantinya akan berakhir setelah lagu selesai dinyanyikan. Kata cublak yang berarti mengetuk, suweng adalah antinganting (jaman dulu) yang dipakai untuk perhiasan perempuan, dari satu lirik ini tidak ada maksud tersembunyi.

\section{b. Nilai Karakter}

\section{1) Nilai Kerjasama}

Permainan ini sangat syarat dengan nuansa kebersamaan karena dimainkan dengan beberapa teman yang lain. Semakin banyak teman akan semakin meriah permainan ini. Permainan Cublak-cublak Suweng dimainkan dengan gerak dan lagu. Lagu dolanan Cublak- 
cublak Suweng yang terdiri atas enam baris, dinyanyikan bersama-sama diikuti dengan gerakan yang mudah. Aturan yang terdapat dalam permainan ini juga dipatuhi oleh seluruh pemain dan secara langsung para pemain menyepakatinya. Apabila ada yang tidak bernyanyi atau tidak bergerak, maka laju permainan ini pun tidak akan baik.

\section{2) Nilai Keproaktifan}

Dalam permainan ini semluruh pemain harus menyanyi dan memutar uwer/ batu. Bagi yang kalah akan menjadi pemain dadi dan berada di tengah dan harus menebak siapa yang menyimpan uwer/batu sesaat lagu selesai dinyanyikan. Si pemain dadi akan berganti dengan lawan pemain yang menyimpan uwer atau batu apabila bisa menebak dengan tepat. Dari penjelasan di atas, nilai kerjasama dan keproaktifan saling berkaitan erat. Pemain yang satu dengan yang lain saling bekerja sama agar permainan bisa lancar 'gayeng' dan hal ini harus disadari oleh masing-masing pemain. Komunikasi antara pemutar uwer terjadi dengan kode/isyarat seperti mengerdipkan mata, bisik-bisik, juga dengan senyuman yang merupakan kode untuk pemain yang lain.

\section{3) Nilai Keresponsifan}

Memainkan dolanan Cublak-cublak Suweng, biasanya anak akan menjadi senang dan memiliki kesempatan untuk bersosialisasi. Pemenuhan kebutuhan akan rasa puas dan senang menjadikan anak merasa nyaman dalam hidup. Rasa senang dan nyaman menjadi salah satu hal yang penting sebagai landasan pembentukan karakter. Rasa senang saat bermain cublakcublak suweng akan membawa hal tersendiri bagi pemain, yakni rasa memiliki peran dalam permainan tersebut. Anak yang pendiam, jahil, bandel, keras kepala, aktif ataupun pasif dalam permainan ini biasanya akan melebur. Hal ini bisa terjadi karena permainan ini bisa riuh ramai dengan adanya kesadaran masing-masing untuk bernyanyi dan menyimpan uwer dengan teliti.

\section{4) Nilai Kreatif}

Nilai kreatif dekat dengan kemampuan kognitif dari individu. Pada saat bermain, peneliti dapat beranggapan bahwa anak (pemain) mulai belajar mengamati dan melakukan gerakan maupun lagu dari dolanan Jamuran. Anak-anak lama-kelamaan akan menjadi tahu dan bisa melakukan dolanan Cublak-cublak Suweng secara berulang-ulang. Permainan ini juga melatih anak untuk lebih kreatif, yaitu dalam permainan ini pemain menggunakan biji atau 
kerikil sebagai pengganti uwer yang sekarang ini susahuntuk ditemukan. Permainan Cubakcublak Suweng ini juga melatih anak untuk berfikir, yaitu ketika anak yang dadi menebak anak yang menggenggam uwer atau biji. Dari uraian di atas, nilai kognitif dapat dijabarkan lagi ke dalam nilai kreatifitas. Anak-anak melakukan dolanan Jamuran, mulai mengenal strategi dan cara untuk mengalahkan ten-teman (kaitannya permainan), semakin sering bermain maka akan semakin kreatif dan mahir.

\section{5) Nilai Kecermatan}

Nilai kecermatan pada permainan ini lebih mengarah pada ketepatan gerak. Nilai kecermatan dari dolanan Cublak-cublak Suweng, yaitu pada saat anak yang dadi membungkuk telungkup, dengan posisi tersebut selain melatih daya tahan otot juga niteni 'mencermati' jatuhnya uwer/batu yang diputar. Bagi anak yang sudah paham, anak yang dadi melakukan posisi tersebut sampai tembang Cublak-cublak Suweng selesai. Setelah tembang selesai, anak yang menyembunyikan maupun yang tidak menyembunyikan uwer, semuanya menggenggam telapak tangganya dengan erat. Dengan demikian maka si pemain dadi ini perlu mencermati dengan baik ciri fisik dan psikis anak yang menyimpan batu atau uwer.

\section{Jamuran}

Istilah jamuran berasal dari bahasa Jawa, yaitu kata jamur yang mendapat akhiran -an. Jamuran ialah semacam tanaman yang berbentuk bulat dan hidupnya menempel pada tanaman lain yang telah mati. Arti kata jamuran dalam dolanan jamuran adalah sutau permainan anak tradhisional yang dalam pelaksanaannya dengan membentuk bulatan seperti jamur.

Dolanan anak jamuran disertai dengan nyanyian dan diakhiri dengan melakukan apa yang disuruh oleh pemain. Asal mula permainan ini tidak ada kepastian yang dapat menjelaskannya.Jumlah pemain yang memainkan ini tidak dibatasi. Semakin banyak jumlah pemainnya, maka permainan ini akan lebih meriah. Permainan ini mudah dimainkan, sehingga anak berusia taman kanak-kanak juga dapat memainkannya. Cara bermain dolanan jamuran ini yaitu dengan membentuk lingkaran dan ada satu anak yang ada ditengahnya.

\section{a. Bentuk Permainan}


Bentuk permaianan jamuran ini berupa gerak dan lagu.Lagu dolanan jamuran yaitu sebagai berikut.

$$
\begin{aligned}
& \text { jamuran....jamuran...ya ge ge thok 'jamuran ya dibuat pura-pura' } \\
& \text { jamur apa ya ge ge thok 'jamur apa ya dibuat pura-pura’ } \\
& \text { Jamur gajih mbejijih sa ara-ara 'jamur gajih mengotori seluruh lapangan' } \\
& \text { sirabadhe jamur apa? 'melesat cepat jamur apa' }
\end{aligned}
$$

Gerak dalam permainan ini yaitu dengan berjalan melingkar mengelilingi disertai dengan bergandengan tangan dan salah satu pemain ada yang berada ditengah, setelah lagu selesai sampai pada kata jamur apa, maka pemain yang berada di tengah menyuruh yang melingkar sesuai dengan keinginannya, seperti menjadi jamur patung. Berarti pemain yang melingkar segera mungkin seolah-olah menjadi patung, dan yang bergerak, tertawa atau tersenyum nantinya akan menjadi ganti pemain yang ditengah. Selanjutnya permainan dimulai dari awal. Permaian ini tidak menggunakan peralatan dalam bermain. Permainan ini hanya memerlukan sebidang tanah luas untuk tempat bermain.

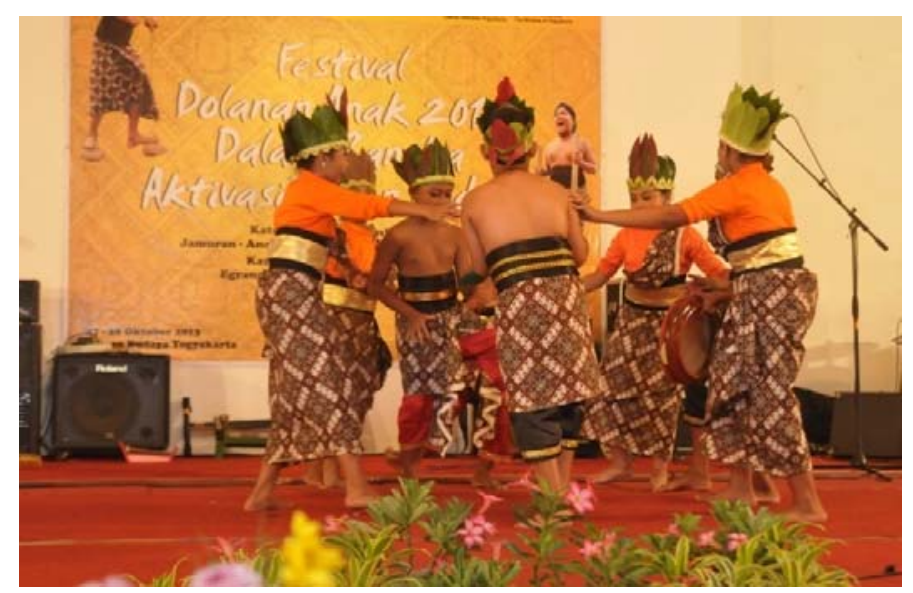

Gambar 2. Jamuran (dok: disparDIY)

\section{b. Nilai/Karakter}

\section{1) Nilai Kerjasama}

Nilai kerjasama yang dapat diambil dari dolanan anak jamuran ini adalah pada saat bermain permainan ini anak-anak akan bernyanyi bersama sehingga muncul suasana yang santai dan menggembirakan. Dengan menyanyi bersama, pada diri anak-anak akan muncul rasa kebersamaan dan juga rasa bersosialisasi yang tinggi dengan teman sebayanya. 


\section{2) Nilai Kreativitas}

Permainan Jamuran ini juga secara tidak langsung mengajarkan anak jiwa seni yaitu dengan bernyanyi, mereka akan dapat mengenal nada-nada yang diyanyikan dalam tembang jamuran dan menyanyikannya dengan kompak. Dalam dolanan jamuran ini, anak-anak juga harus mematuhi peraturan permainan, dengan demikian anak-anak akan diajarkan untuk taat aturan, apalagi peraturan tersebut telah disepakati sebelumnya. Nilai afektif yang lain yang dapat diambil dari permainan jamuran yaitu bahwa permainan ini mengajarkan kekompakan dan kebersamaan. Hal tersebut dapat dilihat pada saat mereka bergandengan melingkar, bernyanyi, dan berputar, dan juga pada saat mereka melakukan gerakan yang diperintah oleh anak yang dadi.

Nilai kreatif permainan Jamuran yaitu dapat dilihat pada saat anak mulai belajar bermain dan bernyanyi. Dengan mengamati dan melakukan gerakan maupun lagu dari dolanan Jamuran anak-anak lama-kelamaan akan menjadi tahu dan bisa melakukan dolanan jamuran secara berulang-ulang. Permainan ini juga melatih anak untuk berfikir, terutama untuk anak yang berada ditengah, anak tersebut akan berfikir akan menyuruh temantemannya untuk menjadi jamur apa ketika lagu selesai dinyanyikan. Anak yang dadi tersebut akan memikirkan strategi supaya teman-temannya sulit melakukan gerakan yang diminta, kemudian menggantikan posisi yang ditengah. Selain itu, permainan ini juga melatih anakanak untuk berfikir cepat, terutama bagi anak-anak yang melingkar dan bernyanyi. Pada saat lagu selesai mereka akan menunggu dan memperhatikan dengan seksama jawaban apa yang akan diucapkan oleh anak yang dadi untuk segera melakukan gerakannya dengan cepat.

\section{3) Nilai Tanggung jawab}

Nilai tanggung jawab dari dari dolanan Jamuran yaitu pada saat mereka melakukan apa yang diperintahkan oleh pemain dadi untuk memperagakan sesuatu. Bagi anak yang tidak dapat bertahan dari permainan ini, maka dia harus mau menjadi pemain dadi. Bagi yang tidak mau di tengah menjadi pemain dadi maka dia harus bertangggungjawab untuk memperagakan dengan baik.

\section{Ancak-ancak Alis}

Dolanan anak ancak-ancak alis juga terkadang disebut dengan Incak-incak Alis. Ancak berarti bambu yang dibuat untuk tempat sesaji ${ }^{\mathrm{i}}$ Sementara incak atau diincaki berarti 
dikelilingi ${ }^{\mathrm{ii}}$.Dari dua permainan sebelumnya, permainana ancak-ancak alis ini sangat jarang ditemukan di masyarakat. Permainan ini merupakan permainan tradisional anak-anak yang bersifat rekreatif, yang dalam proses permainannya biasanya menggunakan istilah-istilah yang berhubungan dengan pertanian, ketentuan jumlah pemain dalam permainan ini tidak dibatasi, karena semakin banyak anak-anak yang terlibat dalam permainan ini akan semakin meriah. Tempat permainan ini dipilih yang luas dan rata.

\section{a. Bentuk Permainan}

Bentuk permainan ini berupa gerak dan lagu. Gerakan dalam permainan ancak-ancak alis yaitu para pemain ada yang menjadi dua petani yang bertugas menjadi gapura dengan tangan diangkat ke atas dan kedua telapak tangan saling bertemu. Peserta yang lain saling berjalan membentuk angka delapan memutari gapura petani, dengan disertai kedua tangan memegang bahu peserta yang berada di depannya. Bersamaan dengan lagu selesai, peserta ada yang tertangkap ditengah gapura dan menjawab pertanyaan lagu terakhir sawahiro lagi apa wong desa.

\section{Lagu: A}

Ancak-ancak alis si Alis kebo janggitan

Anak-anak kebo dhungkul si Dhungkul bambang teyo

Tega rendheng enceng-enceng gaga beluk

Unine pating jerapluk ula apa ula dumung

Gedhene salumbung bandhung

Sawahira lagi apa wong desa?

\section{Lagu: B}

Menyang pasar kadipaten leh-olehe jadah manten

Menyang pasar Ki Jodhog leh-olehe cina bidhog

\section{Lagu: C}

Dikekuru, dilelemu, dicecenggring gering

\section{Lagu $D$}

Kidang lanang apa kidang wadon

Yen lanang mlumpata yen wadon mrobosa 
Permainan Ancak-ancak Alis pada umumnya telah banyak dikenal oleh masyarakat luas hanya saja lagu yang digunakan berbeda. Pada permainan rakyat lebih dikenal sebagai ular naga yang juga dinyanyikan dengan lagu Ular Naga. Lagu Ancak-ancak Alis terdiri dari tiga bagian lagu untuk lagu A, merupakan lagu utama yang dinyanyikan untuk mengikuti gerakan berputar dari para pemain. Lagu A dengan jumlah enam lirik memiliki purwakanthi di setiap barisnya. Permainan kata dan rima di akhir baris ditampilkan untuk menambah keindahan lagu. Sementara isi dari lagu A terdapat di baris terakhir yaitu sawahira lagi apa wong desa? 'sawah kamu sedang apa orang desa? Pada saat lirik ini berhenti dinyanyikan maka gerakan kedua pemain selaku petani menangkap badan dari salah satu pemain yang berhenti di tepat tengah gapura, begitu seterusnya hingga seluruh pemain habis.

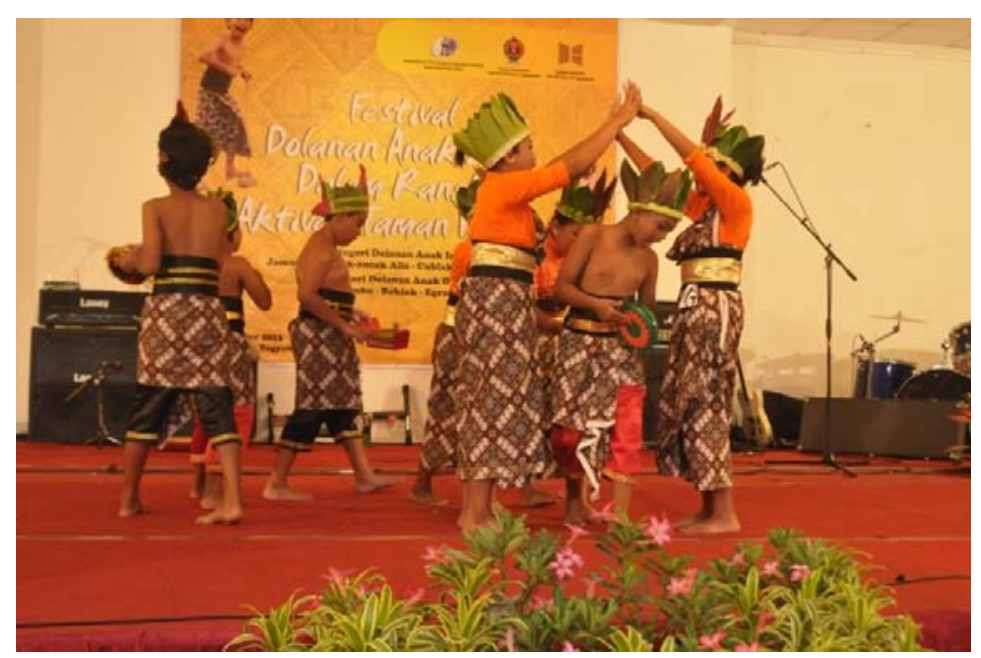

Gambar 3. Ancak-ancak Alis (dok: Dispar DIY)

\section{b. Nilai/ Karakter}

\section{1) Nilai Kerja sama}

Nilai kerja sama permainan Ancak-ancak Alis yaitu saat menyanyi dan membuat barisan panjang. Permainan ini dimainkan minimal 5 anak dan yang 2 menjadi pagar/penunggu. Permainan akan semakin meriah apabila diikuti banyak peserta. Permainan Ancak-ancak Alis dimainkan dengan gerak dan lagu. Lagu dolanan Ancak-ancak Alis yang terdiri dari 3 buah lagu secara berurutan, dinyanyikan bersama-sama diikuti dengan gerakan yang mudah. Dengan gerak dan lagu yang dinyanyikan dengan bersama-sama dan kompak maka suasana menjadi menggembirakan. 


\section{2) Nilai Keadilan}

Menyanyi bersama dalam dolanan ini akan memunculkan rasa kebersamaan dan juga rasa bersosialisasi yang tinggi dengan teman sebayanya. Dalam permainan ini, anak-anak juga belajar untuk memilih kubu mana yang akan dipilih dengan mempertimbangkan keadilan setiap kubu sehingga jumlah pemainnya sama.

\section{3) Nilai Kecermatan}

Nilai kecermatan dari permainan Ancak-ancak Alis yaitu dapat dilihat pada saat anak mulai belajar mengamati dan melakukan gerakan maupun lagu dari Ancak-ancak Alis anakanak lama-kelamaan akan menjadi tahu dan bisa melakukan dolanan Ancak-ancak Alis secara berulang-ulang. Permainan ini juga melatih anak untuk mentaati aturan permainan Ancak-ancak Alis, apalagi ada aturan-aturan yang telah disepakati sebelumnya.

\section{4) Nilai Ketekunan}

Nilai ketekunan dari dolanan Ancak-ancak Alis yaitu pada saat anak melakukan putaran dengan membentuk angka delapan sambil bernyanyi. Ketekuanan dilihat dari bagaimana anak-anak mencermati tiap gerakan yang dilakukan berulang-ulang. Selain untuk melatih pergangan otok kaki dengan berjalan agak cepat supaya masing-masing individu tidak tertahan di gapura petani. Pada dolanan Ancak-ancak Alis ini juga setiap anak memegang pinggang teman didepannya, dengan demikian berarti dengan permainan ancakancak alis ini setiap anak harus tekun melatih kefokusan agar tangan tidak lepas dari pinggang teman di depannya.

\section{E. KESIMPULAN}

Setelah melakukan rangkaian proses penelitian, yaitu pengumpulan data, klasifikasi data dan analisis data, maka simpulan data dari hal-hal yang ditemukan sesuai dengan tujuan awal dari penelitian adalah sebagai berikut.

1. Festival Dolanan Anak di Taman Budaya Yogyakarta tahun 2013, merupakan bentuk pertunjukkan yang difungsikan untuk mengenalkan dan melestarikan seni tradisi masyarakat Jawa, khususnya Yogyakarta. Dari beberapa regu penampil dipilih tampilan terbaik yaitu Sanggar Seni Laras, Samigaluh Kulon Progo. Seni 
pertunjukkan dapat dikatakan baik apabila memperhatikan beberapa hal sebagai berikut: etika, estetika, tata busana, tata ruang/setting, dan peralatan/equipment.

2. Dari penampilan dolanan anak ditemukan nilai-nilai karakter dari gerakan dan lirik yang dimainkan. Ketiga bentuk dolanan, yakni Cublak-Cublak Suweng, Jamuran dan Ancak-ancak Alis merupakan dolanan asli Jawa yang menggunakan nyanyian dalam permainannya. Selain itu ketiga permainan tersebut juga memiliki gerakan yang menginterpretasikan dari permainan tersebut.

3. Nilai karakter secara umum terdiri dari afektif, kognitif dan psikomotorik, namun penjabaran dari masing-masing dolanan terdiri atas nilai: kecermatan, kerjasama, keresponsifan, keproaktifan, kreatif, ketekunan, dan keadilan. Dalam bahasan seni tari ketiga nilai itu lebih dikenal wiraga (psikomotorik), wirama (afektif), dan wirasa (kognitif). Masing-masing dolanan anak memiliki ketiga unsur nilai yang sangat mendukung untuk pengembangan diri anak-anak.

\section{DAFTAR PUSTAKA}

Ahimsha-Putra, Heddy Sri. 1999. Permainan Tradisional di Jawa dan Tantangan dalam Era Kesejagadan dalam Prosiding Dolanan Anak Refleksi Budaya dan Wahana Tumbuh Kembang Anak, halaman 9-18. Yogyakarta: Plan Internasiona IndonesiaLPM Sosiatri Fisipol UGM.

Barthes, Roland. 1970. S/Z. Terjemahan Richard Howard. Great Britain: Basill Blackwell.

Dinas Pariwisata DIY. 2013. Laporan Penyelenggaraan Festival Dolanan Anak Dalam Rangka Aktivisi Taman Budaya Yogyakarta. Yogyakarta: Dinas Pariwisata Yogyakarta.

Murgiyanto, Sal. 1994. Pendidikan Tari Kita, Kenyataan, Bandingan dan Harapan. Jakarta: PT. Dunia Pustaka Jaya

Tim Penulis, 1983. Permainan Anak-anak Daerah Istimewa Yogyakarta. Yogyakarta: Depdikbud.

Sujarno, dkk. 2011. Pemanfaatan Permainan Tradisional Dalam Pembentukan Karakter Anak. Yogyakarta: BPNB Yogyakarta. 